\title{
Análise quantitativa dos tecidos gengivais de ratos tratados com fenitoína e ciclosporina
}

\section{Quantitative analysis of gingival tissues of rats treated with phenytoin and cyclosporine}

\author{
Luís Carlos SPOLIDORIO* \\ Heron Fernando de Souza GONZAGA* \\ Denise M. P. SPOLIDORIO*
}

\begin{abstract}
SPOLIDORIO, L. C.; GONZAGA, H. F. de S.; SPOLIDORIO, D. M. P. Análise quantitativa dos tecidos gengivais de ratos tratados com fenitoína e ciclosporina. Pesqui Odontol Bras, v. 14, n. 4, p. 327-333, out./dez. 2000.

Os aumentos gengivais podem ser decorrentes de reações teciduais a estímulos idiopáticos, patológicos e farmacológicos. O objetivo desse trabalho foi avaliar morfometricamente e estereologicamente a ação da fenitoína (Fen) e ciclosporina $(\mathrm{CsA})$ sobre os tecidos gengivais de ratos. Dez ratos receberam, por via intraperitonial, Fen na dose inicial de $2 \mathrm{mg} / \mathrm{kg}$ de peso corporal/dia, aumentando $2 \mathrm{mg}$ a cada duas semanas, durante 60 dias. Em outros 10 ratos, administraram-se, por via subcutânea, $10 \mathrm{mg} / \mathrm{kg}$ de peso corporal/dia de CsA, durante o mesmo periodo do grupo anterior. Os valores morfométricos e estereométricos dos tecidos gengivais dos ratos tratados com CsA foram significativamente maiores quando comparado com os valores dos tecidos gengivais do grupo tratado com Fen. Esses resultados sugerem que a CsA na dose utilizada é mais eficaz no desenvolvimento do aumento gengival em ratos, podendo estar atuando na proliferação de fibroblastos e no desequilíbrio fisiológico da síntese de fibras colágenas.
\end{abstract}

UNITERMOS: Fibromatose gengival; Fenitoína; Ciclosporina.

\section{INTRODUÇÃO}

A associação entre alterações gengivais e drogas foi primeiramente descrita por KIMBALL ${ }^{12}$ em 1939. Inicialmente, o aumento gengival induzido por droga foi sinônimo de hiperplasia pela fenitoína $(\mathrm{Fen})^{1}$. Atualmente, outras drogas são também conhecidas como responsáveis pelo aumento gengival, como os bloqueadores do canal de cálcio e ciclosporina $(\mathrm{CsA})^{15}$.

A Fen é usada principalmente no tratamento de convulsões ${ }^{16}$ e eventualmente no tratamento de arritmias cardiacas, particularmente nas arritmias ventriculares ${ }^{4}$. A CsA é um macrolídeo fúngico com propriedades imunossupressivas, cuja ação consiste na interferência na ativação dos genes que expressam algumas linfocinas, suprimindo principalmente a produção de IL-2 e reduzindo a expressão de receptores para essa interleucina, nos linfócitos em processo de ativação. Devido as suas propriedades imunossupressivas, a CsA é utilizada principalmente na profilaxia e tratamento da rejeição de transplantes alogênicos e eventual- mente no tratamento de algumas doenças autoimunes $^{20}$.

A prevalência do aumento gengival induzido por drogas é variável e controverso, aventa-se a hipótese que tal variabilidade possa estar relacionada com a dosagem da droga ${ }^{8}$, concentração da droga tanto plasmática ${ }^{11,23}$, como na saliva ${ }^{5,14}$ e presença de placa bacteriana e conseqüentemente inflamação ${ }^{13,18,23}$.

O mecanismo do aumento gengival induzido por drogas ainda é incerto e as informações são conflitantes. Postula-se que ocorra estimulação na proliferação de algumas populações de fibroblastos, o que de certa forma justificaria a suscetibilidade individual por essas drogas ${ }^{1,9,22}$. Por outro lado, atribuem o aumento gengival induzido por drogas ao acúmulo de proteínas na matriz extracelular, principalmente do colágeno ${ }^{22}$. Desequilíbrios entre a síntese e a degradação da matriz extracelular podem favorecer o acúmulo de colágeno e outras macromoléculas na matriz extracelular do tecido gengival ${ }^{10,26}$.

O propósito deste trabalho foi avaliar morfome-

\footnotetext{
* Professores Assistentes Doutores da Disciplina de Patologia da Faculdade de Odontologia de Araraquara da UNESP.
} 
SPOLIDORIO, L. C.; GONZAGA, H. F. de S.; SPOLIDORIO, D. M. P. Análise quantitativa dos tecidos gengivais de ratos tratados com fenitoína e ciclosporina. Pesqui Odontol Bras, v. 14, n. 4, p. 327-333, out./dez. 2000.

tricamente e estereometricamente a ação da Fen e CsA sobre os tecidos gengivais de ratos.

\section{MATERIAL E MÉTODOS}

Foram utilizados 30 ratos (Ratus norvergicus albinus, variedade Wistar) machos, jovens, com peso inicial de aproximadamente $50 \mathrm{~g}$, tratados com água e ração ad libitum. Os ratos foram distribuídos aleatoriamente em 4 grupos, sendo 2 grupos de 5 e 2 grupos de 10, e submetidos aos tratamentos como ilustra a Tabela 1 .

\section{Tratamento com CsA e Fen}

A CsA*, concentração de $50 \mathrm{mg} / \mathrm{ml}$, foi diluída com solução de $\mathrm{NaCl}$ a $0,9 \%$ obtendo-se uma concentração final de $10 \mathrm{mg} / \mathrm{ml}$. Foram administrados $10 \mathrm{mg} / \mathrm{kg}$ de peso corporal/dia, por via subcutânea durante $60 \operatorname{dias}^{27}$. A Fen** foi injetada diariamente por via intraperitonial, durante 60 dias. Durante as primeiras duas semanas foram administrados $2 \mathrm{mg} / \mathrm{kg}$ de peso corporal/dia aumentando $2 \mathrm{mg}$ a cada 2 semanas. Nas duas últimas semanas, os ratos receberam diariamente $10 \mathrm{mg} / \mathrm{kg}$ de peso corporal/dia ${ }^{18}$. Dez ratos controle receberam procedimentos de forma similar com solução de $\mathrm{NaCl}$ a $0,9 \%$.

\section{Processamento histológico}

Os ratos foram sacrificados por deslocamento cervical e as mandíbulas removidas e dissecadas. A descalcificação foi realizada em solução de citrato de sódio a $20 \%$ e ácido fórmico a $50 \%$ em partes iguais e incluídas em parafina rotineiramente. Secções transversais seriadas com $6 \mu \mathrm{m}$ de espessura foram coradas com $\mathrm{H}$. E.

\section{Morfometria}

As medidas morfométricas foram feitas na gengiva livre, na região de primeiro molar inferior, tan-

TABELA 1 - Distribuição dos grupos de ratos submetidos $(+)$ ou não $(-)$ aos tratamentos com CsA ou Fen. Os grupos I e II foram considerados controle.

\begin{tabular}{c|c|c}
\hline \hline Grupo & CsA & Fen \\
\hline I $(\mathrm{n}=5)$ & - & - \\
\hline II $(\mathrm{n}=5)$ & - & - \\
\hline III $(\mathrm{n}=10)$ & + & - \\
\hline IV $(\mathrm{n}=10)$ & - & + \\
\hline \hline
\end{tabular}

to na face vestibular como na face lingual, nas hemimandibulas direita e esquerda dos ratos de todos os grupos. Utilizou-se um programa analisador de imagens (Mocha, Jandel Scientific San Rafael, CA, EUA), acoplado a um microscópio de luz Diastar (Cambridge Instruments, Buffalo, NY, EUA), com objetiva de $10 \mathrm{X}$. Foram mensurados aproximadamente 20 cortes, distantes um corte do outro aproximadamente $60 \mu \mathrm{m}$ (10 cortes). Os resultados foram expressos em pixels e transformados em $\mu \mathrm{m}$. De acordo com BERGLUNG et al. ${ }^{3}$ (1991), foram estabelecidos pontos morfológicos na gengiva marginal livre. As mensurações foram feitas a partir desses pontos, como ilustrado na Figura 1.

\section{Estereologia}

A determinação da densidade volumétrica de fibroblastos (identificados como células fusiformes, núcleo alongado), fibras colágenas, e outras estruturas, que correspondiam a outros tipos celulares, vasos sanguíneos e espaços vazios foram feitas com o auxílio de uma objetiva de $100 \mathrm{X}$, onde uma moldura quadriculada com área por ponto definida era sobreposta às áreas das imagens capturadas do microscópio e projetadas no monitor. A quantificação foi feita com auxílio de um programa analisador de imagens (Mocha, Jandel Scientific San Rafael, CA, EUA), acoplado a um microscópio de luz Diastar (Cambridge Instruments, Buffalo, NY, EUA). Foram contados 25 pontos coincidentes sobre as estruturas histológicas em 16 cortes da

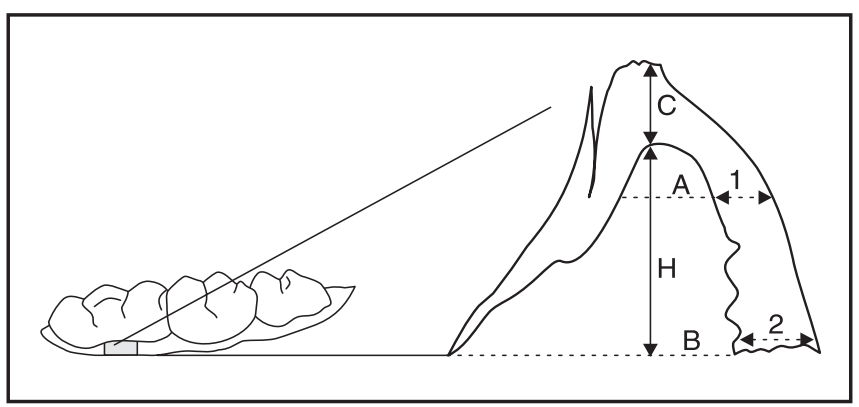

FIGURA 1 - Esquema da gengiva marginal livre de rato, mostrando os pontos de referência usados para as medidas morfométricas do epitélio bucal e tecido conjuntivo. $\mathrm{C}=$ altura do epitélio da crista gengival; $1,2=$ epitélio bucal nas porções coronária e basal; $\mathrm{H}$ = altura do tecido conjuntivo da região média; $\mathrm{A}=$ largura do tecido conjuntivo na região média; $\mathrm{B}=$ largura do tecido conjuntivo na região basal.

* Novartis.

** Cristalia. 
SPOLIDORIO, L. C.; GONZAGA, H. F. de S.; SPOLIDORIO, D. M. P. Análise quantitativa dos tecidos gengivais de ratos tratados com fenitoína e ciclosporina. Pesqui Odontol Bras, v. 14, n. 4, p. 327-333, out./dez. 2000.

TABELA 2 - Médias das medidas morfométricas ( $\mu \mathrm{m} \pm$ desvio-padrão) de estruturas da gengiva da face vestibular dos primeiros molares inferiores, em relação aos vários tratamentos.

\begin{tabular}{l|c|c|c|c|c}
\hline \hline \multicolumn{1}{c|}{ Tratamentos } & Crista epitelial & Epitélio bucal & Altura & Largura A & Largura B \\
\hline Controle & $50,32 \pm 0,12$ & $41,89 \pm 0,87$ & $410,23 \pm 1,11$ & $172,62 \pm 0,83$ & $151,33 \pm 0,65$ \\
\hline Fen & $50,50 \pm 0,28$ & $42,91 \pm 0,66$ & $412,67 \pm 0,98$ & $175,96 \pm 0,78$ & $150,10 \pm 0,82$ \\
\hline CsA & $136,45^{*} \pm 1,54$ & $99,90^{*} \pm 0,77$ & $998,76^{*} \pm 1,05$ & $348,98^{*} \pm 1,34$ & $302,45 \pm 1,05$ \\
\hline \hline
\end{tabular}

*Estatisticamente significativo pelo teste de Tukey ao nivel de 5\%.

TABELA 3 - Médias das medidas morfométricas ( $\mu \mathrm{m} \pm$ desvio-padrão), de estruturas da gengiva da face lingual dos primeiros molares inferiores, em relação aos vários tratamentos.

\begin{tabular}{l|c|c|c|c|c}
\hline \hline \multicolumn{1}{c|}{ Tratamentos } & Crista epitelial & Epitélio bucal & Altura & Largura A & Largura B \\
\hline Controle & $47,47 \pm 0,75$ & $40,45 \pm 0,55$ & $268,25 \pm 1,20$ & $156,33 \pm 0,67$ & $138,45 \pm 1,02$ \\
\hline Fen & $47,23 \pm 0,89$ & $41,03 \pm 1,09$ & $266,87 \pm 0,64$ & $158,23 \pm 0,88$ & $140,11 \pm 0,54$ \\
\hline CsA & $98,66^{*} \pm 1,30$ & $92,30^{*} \pm 0,85$ & $521,70^{*} \pm 1,15$ & $271,95^{*} \pm 0,95$ & $258,02^{*} \pm 0,77$ \\
\hline \hline
\end{tabular}

*Estatisticamente significativo pelo teste de Tukey ao nivel de 5\%.

gengiva da face vestibular e 16 cortes da gengiva da face lingual (cada corte correspondia a um campo), numa distância de 10 cortes entre uma contagem e outra, perfazendo um total de 400 pontos na gengiva da face vestibular e 400 pontos na gengiva da face lingual em ambas hemimandíbulas por animal. A determinação da densidade de volume das estruturas em análise, baseou-se nos princípios de WEIBEL ${ }^{28}$ (1969), cujo volume relativo (\%) das estruturas em análise foi calculado através da fórmula: $P p i=P i / P(P p i=$ densidade de volume das estruturas das áreas, $\mathrm{Pi}$ = soma do número de pontos coincidentes sobre cada estrutura e $\mathrm{P}=$ número total de pontos do retículo, multiplicando-se o número de pontos do retículo pelo número de campos examinados).

\section{Análise estatística}

Para a análise dos dados, foi aplicado o teste de variância ANOVA. Quando acusou diferença significante, essa análise foi complementada pelo teste de Tukey ao nivel de 5\%.

\section{RESULTADOS \\ Morfometria do epitélio e tecido conjuntivo da gengiva da face vestibular e lingual}

As médias das medidas morfométricas da crista epitelial, epitélio bucal, altura e larguras A e B do tecido conjuntivo foram semelhantes nos grupos controle e nos tratados com Fen. O tratamento com CsA aumentou significativamente as dimensões lineares do epitélio e tecido conjuntivo da gen- giva vestibular e lingual de todos os ratos (Tabelas 2 e 3 ).

\section{Quantificação das áreas do epitélio bucal, tecido conjuntivo das gengivas das faces vestibular e lingual}

Sessenta dias após o tratamento com CsA, as áreas do epitélio e tecido conjuntivo da gengiva da face vestibular e lingual aumentaram em relação às áreas do epitélio e tecido conjuntivo das gengivas dos ratos tratados com Fen e controle. Nos aumentos gengivais induzidos pela CsA, as áreas do epitélio e o tecido conjuntivo da face vestibular eram maiores que as áreas da face lingual, como ilustrado nas Tabelas 4 e 5 .

\section{Estereologia}

As Tabelas 6 e 7 expressam os resultados obtidos da análise estereológica para a avaliação da densidade volumétrica (\%) de fibroblastos, fibras colágenas e outras estruturas da gengiva vestibular e lingual dos primeiros molares inferiores, dos ratos submetidos aos vários tipos de tratamento. As densidades volumétricas de fibroblastos, fibras colágenas e outras estruturas foram semelhantes entre os grupos controle e o tratado com Fen, nas gengivas da face vestibular e lingual. As densidades volumétricas de fibroblastos e fibras colágenas foram significativamente maiores nas gengivas dos ratos tratados com CsA, enquanto a densidade volumétrica de outras estruturas foi menor. 
SPOLIDORIO, L. C.; GONZAGA, H. F. de S.; SPOLIDORIO, D. M. P. Análise quantitativa dos tecidos gengivais de ratos tratados com fenitoína e ciclosporina. Pesqui Odontol Bras, v. 14, n. 4, p. 327-333, out./dez. 2000.

TABELA 4 - Médias das áreas $\left(\mu \mathrm{m}^{2}\right)$ do epitélio bucal, do tecido conjuntivo e área total da gengiva da face vestibular, em relação aos diversos tratamentos.

\begin{tabular}{l|c|c|c}
\hline \hline Tratamentos & $\begin{array}{c}\text { Epitélio } \\
\text { bucal }\end{array}$ & $\begin{array}{c}\text { Tecido } \\
\text { conjuntivo }\end{array}$ & Total \\
\hline Controle & 28.470 & 40.420 & 68.890 \\
\hline Fen & 29.180 & 40.966 & 68.100 \\
\hline CsA & $86.603 *$ & $143.950 *$ & $230.553^{*}$ \\
\hline \hline
\end{tabular}

*Estatisticamente significativo pelo teste de Tukey ao nivel de $5 \%$.

TABELA 5 - Médias das áreas $\left(\mu \mathrm{m}^{2}\right)$ do epitélio bucal, do tecido conjuntivo e área total da gengiva da face lingual, em relação aos diversos tratamentos.

\begin{tabular}{l|c|c|c}
\hline \hline Tratamentos & $\begin{array}{c}\text { Epitélio } \\
\text { Bucal }\end{array}$ & $\begin{array}{c}\text { Tecido } \\
\text { conjuntivo }\end{array}$ & Total \\
\hline Controle & 13.590 & 18.537 & 32.127 \\
\hline Fen & 13.990 & 19.131 & 33.121 \\
\hline CsA & $50.276^{*}$ & $58.707^{*}$ & $108.983^{*}$ \\
\hline \hline
\end{tabular}

*Estatisticamente significativo pelo teste de Tukey ao nivel de $5 \%$.

\section{DISCUSSÃO E CONCLUSÕES}

O presente trabalho avaliou o aumento gengival por meio da administração sistêmica de Fen e CsA por 60 dias.

Primeiramente, analisou-se quantitativamente, por meio de medidas morfométricas, o epitélio e o tecido conjuntivo, assim como as áreas das gengivas vestibular e lingual, da região de primeiro molar inferior dos ratos. É importante que os pontos morfológicos para tais mensurações sejam precisos e invariáveis; neste trabalho, esse fator foi estabelecido com cautela, com todas as leituras seguindo orientações dos pontos preestabelecidos, em todos os cortes medidos, permitindo avaliações comparativas entre os grupos.

Houve significativo aumento das dimensões do epitélio, da altura e largura A e B do tecido conjuntivo e das áreas das gengivas dos ratos tratados com CsA, o mesmo não acontecendo com os ratos tratados com Fen. Os resultados também mostraram que as dimensões dos tecidos gengivais da face vestibular são maiores que as da lingual nos ratos tratados com CsA. Técnicas semelhantes foram utilizadas por FISCHER; KLINGE ${ }^{7}$ (1994), para mensurar cortes histológicos corados com H. E., do aumento gengival induzido pela CsA em
TABELA 6 - Médias das medidas estereométricas $(\mu \mathrm{m} \pm$ desvio-padrão), de fibroblastos, fibras colágenas e outras estruturas da face vestibular dos primeiros molares inferiores, em relação aos vários tratamentos.

\begin{tabular}{c|c|c|c}
\hline \hline Tratamentos & $\begin{array}{c}\% \text { de } \\
\text { fibroblastos }\end{array}$ & $\begin{array}{c}\% \text { de fibras } \\
\text { colágenas }\end{array}$ & $\begin{array}{c}\% \text { de outras } \\
\text { estruturas }\end{array}$ \\
\hline Controle & $11,82 \pm 0,55$ & $66,57 \pm 0,80$ & $21,60 \pm 0,67$ \\
\hline Fen & $12,01 \pm 0,76$ & $67,08 \pm 0,54$ & $20,91 \pm 0,25$ \\
\hline CsA & $13,65^{*} \pm 0,90$ & $71,67 * \pm 0,39$ & $14,67 * \pm 1,01$ \\
\hline \hline
\end{tabular}

*Estatisticamente significativo pelo teste de Tukey ao nivel de $5 \%$.

TABELA 7 - Médias das medidas estereométricas $(\mu \mathrm{m} \pm$ desvio-padrão), de fibroblastos, fibras colágenas e outras estruturas da face lingual dos primeiros molares inferiores, em relação aos vários tratamentos.

\begin{tabular}{c|c|c|c}
\hline \hline Tratamentos & $\begin{array}{c}\% \text { de } \\
\text { fibroblastos }\end{array}$ & $\begin{array}{c}\% \text { de fibras } \\
\text { colágenas }\end{array}$ & $\begin{array}{c}\% \text { de outras } \\
\text { estruturas }\end{array}$ \\
\hline Controle & $11,90 \pm 0,90$ & $67,60 \pm 0,90$ & $20,50 \pm 1,10$ \\
\hline Fen & $12,22 \pm 0,69$ & $66,04 \pm 1,11$ & $21,74 \pm 0,99$ \\
\hline CsA & $13,12 * \pm 1,10$ & $71,75^{*} \pm 1,21$ & $15,12 * \pm 1,51$ \\
\hline \hline
\end{tabular}

*Estatisticamente significativo pelo teste de Tukey ao nivel de $5 \%$.

furão, cujos valores das medidas morfométricas do epitélio bucal e epitélio juncional indicaram aumento em suas dimensões.

Vários relatos estabelecem a associação do aumento gengival induzido por drogas a fatores coadjuvantes para seu desenvolvimento como dosagem $^{8}$ e conseqüente concentração da droga tanto plasmática $^{11,23}$, como salivar ${ }^{5,14}$, e placa bacteriana com conseqüente inflamação ${ }^{13,18,23}$. As doses de Fen usadas nesse experimento foram as mesmas estipuladas por NASCIMENTO et al. ${ }^{18}$ (1985), e a dose de CsA foi estabelecida por WASSEF et al. ${ }^{27}$ (1985), cujos resultados mostraram que a dosagem de 10 $\mathrm{mg} / \mathrm{kg}$ de peso corporal/dia em ratos induzem concentração plasmática constante e não induzem toxicidade.

Os resultados do presente trabalho mostraram que o tratamento com Fen, na dose utilizada, foi pouco eficaz na indução do aumento gengival em ratos; resultados semelhantes foram observados por NASCIMENTO et al. ${ }^{18}$ (1985). Esses autores só observaram aumento gengival quando associaram a Fen com acúmulo experimental de placa bacteriana e conseqüente inflamação gengival. Por outro 
SPOLIDORIO, L. C.; GONZAGA, H. F. de S.; SPOLIDORIO, D. M. P. Análise quantitativa dos tecidos gengivais de ratos tratados com fenitoína e ciclosporina. Pesqui Odontol Bras, v. 14, n. 4, p. 327-333, out./dez. 2000.

lado, $100 \%$ dos ratos tratados com CsA desenvolveram aumento gengival confirmando os achados de KITAMURA et al. ${ }^{13}$ (1990). SOMACARRERA et $a .^{24}$ (1994) sugeriram que o fator básico que influencia a severidade do aumento gengival são a concentração de CsA no sangue e os níveis de placa dental e gengivite.

O mecanismo de ação do aumento gengival induzido por drogas ainda é enigmático, mas postula-se que seja devido à estimulação direta ou indireta na proliferação de algumas populações de fibroblastos ${ }^{2,17,21}$, aumento da sintese protéica da matriz ${ }^{19,29}$ extracelular ou ainda inibição da atividade das metaloproteinases ${ }^{25}$. Eventualmente, esses fatores podem atuar simultaneamente, em maior ou menor grau, dependendo do $\mathrm{caso}^{25}$. Os vários estudos existentes até o momento explorando os mecanismos de ação dessas drogas sobre o indice de proliferação de fibroblastos, sintese protéica e atividade colagenolítica têm apresentado resultados controversos; portanto, a quantificação da população de fibroblastos e matriz extracelular do aumento gengival permanece obscuro, existindo poucos estudos e com resultados conflitantes ${ }^{15}$.

Os dados obtidos neste trabalho revelam que o tecido conjuntivo da gengiva marginal dos ratos tratados com CsA apresenta maior densidade volumétrica de fibroblastos e de fibras colágenas, quando comparado com o grupo controle e o grupo tratado com Fen. Alguns estudos in vitro têm demonstrado a influência da CsA e Fen estimulando a proliferação de subpopulações de fibroblas$\operatorname{tos}^{6,22,26}$. Outros autores sugeriram que in vivo a CsA e a Fen não influenciam diretamente o metabolismo dos fibroblastos, atuando através de vias indiretas, associadas a liberação de mediadores da inflamação ou produtos bacterianos, enfatizando que o aumento gengival induzido pela CsA ocorre, com maior freqüência, em regiões onde há maior índice de placa bacteriana e conseqüentemente maior grau de inflamação ${ }^{9,11}$. WILLERHAUSENZÖNNCHEN et al..$^{29}$ (1992) realizaram estudo incubando fibroblastos gengivais com CsA na concentração de $1.000 \mathrm{ng} / \mathrm{ml}$ por $72 \mathrm{~h}$ e por 6 semanas.
Verificaram que no período de 72 horas não houve alteração significante no número de células, entretanto, no período experimental de 6 semanas, a CsA estimulou a proliferação celular, considerando esses resultados evidência da estimulação direta da CsA sobre a proliferação de fibroblastos gengivais sensiveis. Neste trabalho, todos os ratos responderam ao tratamento com CsA podendo-se aventar a hipótese de que fibroblastos das gengivas de ratos de variedade Wistar são geneticamente sensiveis à ação da CsA, e não são sensíveis à Fen, dentro das condições deste experimento.

Os resultados apresentados no presente trabalho indicam aumento da densidade volumétrica de fibras colágenas nas gengivas de ratos tratados com CsA, mas não com Fen. O acúmulo de colágeno pode resultar de um estímulo na sua sintese e/ou diminuição da sua degradação. De acordo com TIPTON et al. ${ }^{26}$ (1991), o aumento da síntese de colágeno, a baixa produção de colagenase ou ainda o aumento da produção de TIMPs podem levar a uma deposição exagerada de colágeno no tecido gengival. Os mesmos autores relatam ainda que o efeito da CsA sobre a atividade colagenolitica aparentemente depende do doador da amostra, da presença de subpopulações celulares suscetiveis e também da concentração plasmática da droga. Em 1982, HASSEL ${ }^{9}$ demostrou, através de radioimunoensaios, que fibroblastos de indivíduos com aumento gengival causado por Fen produziram grandes quantidades de colagenase, no entanto, essa enzima era pouco eficiente para a degradação de colágeno in vitro.

Portanto o mecanismo do aumento gengival induzido por drogas é intensamente discutido, merecendo estudos subseqüentes; contudo podemos concluir através dos nossos resultados que os aumentos gengivais são dose-dependentes e que a CsA na dose utilizada é um modelo de estudo viável para subseqüentes estudos do aumento gengival induzido por drogas. Os resultados sugerem também atuação da CsA sobre a proliferação de fibroblastos e provavelmente desequilíbrio fisiológico da sintese ou degradação de fibras colágenas. 
SPOLIDORIO, L. C.; GONZAGA, H. F. de S.; SPOLIDORIO, D. M. P. Análise quantitativa dos tecidos gengivais de ratos tratados com fenitoína e ciclosporina. Pesqui Odontol Bras, v. 14, n. 4, p. 327-333, out./dez. 2000.

SPOLIDORIO, L. C.; GONZAGA, H. F. de S.; SPOLIDORIO, D. M. P. Quantitative analysis of gingival tissues of rats treated with phenytoin and cyclosporine. Pesqui Odontol Bras, v. 14, n. 4, p. 327-333, oct./dez. 2000.

Reactions to a number of idiopathic, pathological and pharmacological stimuli may result in overgrowth of gingiva, whose mechanisms have not been established yet. The aim of the present work was to evaluate morphometrically and stereologically the effect of phenytoin (PHT) and cyclosporine (Cs) on the gingival tissues of rats. Ten rats received daily IP injection of PHT, $2 \mathrm{mg} / \mathrm{kg}$ of body weight/day, which was increased in $2 \mathrm{mg}$ at each two weeks, during 60 days. Ten rats received $10 \mathrm{mg} / \mathrm{kg}$ of body weight/day of $\mathrm{Cs}$, subcutaneously, during the same period of the previous group. All rats treated with Cs developed gingival overgrowth, with increased thickness of the epithelium, height and wideness of connective tissues, as well as, increased density of fibroblasts and collagen fibers, when compared with the rats treated with PHT and with the control. These results suggest that Cs, in the used dose, is more efficient in the development of gingival overgrowth in rats. Cs-induced gingival overgrowth is a tissue with an altered composition, characterized by increasing of the density of fibroblasts and by physiologic unbalance of collagen synthesis.

UNITERMS: Fibromatosis, gingival; Phenytoin; Cyclosporine.

\section{REFERÊNCIAS BIBLIOGRÁFICAS}

1. ADDY, V.; McELNAY, J.; EYRE, D. Risk factors in phenytoin-induced gingival hyperplasia. J Periodontol, v. 54, n. 2, p. 373-377, May 1983.

2. BARTOLD, P. Regulation of human gingival fibroblasts growth and synthetic activity by cyclosporin-A in vitro. $\mathbf{J}$ Periodontal Res, v. 24, n. 5, p. 314-321, Oct. 1989.

3. BERGLUNCH, T.; LINDHE, J.; STERRET, J. D. Clinical and structural characteristics of tissues in young and old dogs. J Clin Periodontol, v. 18, n. 6, p. 616-623, Sept. 1991.

4. BREDFELDT, G. W. Phenytoin-induced hyperplasia found in edentulous patients. J Am Dent Assoc, v. 123, n. 8, p. 61-64, Feb. 1992.

5. COLEY, C.; JARVIS, K.; HASSEL, T. Effect of cyclosporin-A on human gingival fibroblasts in vitro. J Dent Res, v. 65 , p. 228-377, Feb. 1983.

6. CONARD, G. J.; JEFFERY, H.; BOSHES, L. et al. Levels of 5,5-diphenylhydantoin and its major metabolite in human serum, saliva and hyperplastic gingiva. J Dent Res, v. 53, n. 4 p. 1323-1329, Aug. 1974.

7. FISCHER, R. G.; KLINGE, B. Clinical and histological evaluation of ligature-induced periodontal breakdown in domestic ferrets immunosuppressed by cyclosporin-A. J Clin Periodontol, v. 21, p. 240-249, Feb. 1994

8. FU, E.; NIEH, S.; CHANG, H. Dose-dependent gingival overgrowth induced by cyclosporin in rats. $\mathbf{J}$ Periodontol, v. 66, p. 594-598, Jun. 1995.

9. HASSEL, T. M. Evidence for production of an inactive collagenase by fibroblasts from phenytoin-enlarged human gingiva. J Oral Pathol, v. 11, p. 310-317, Aug. 1982.

10. HASSEL, T.; GILBERT, G. Phenytoin sensitivity of fibroblasts as the basis for susceptibility to gingival enlargement. Am J Pathol, v. 112, p. 218-223, Sept. 1983.

11. JAMES, J. A.; IRWIN, C. R.; LINDEN, G. J. The effects of culture environment on the response of human gingival fibroblasts to cyclosporin-A. J Periodontol, v. 66, p. 339-344, Mar. 1995.

12. KIMBALL, O. The treatment of epilepsy with sodium diphenylhydantoinate. J Am Med Assoc, v. 112, p. 1244-1245, Mar. 1939
13. KITAMURA, K.; KATO, K.; YOSHIDA, M. et al. Cyclosporin-A-induced gingival overgrowth - strain differences in the rats. Arch Oral Biol, v. 35, p. 483-486, Mar. 1990.

14. McGAW, W. T.; PORTER, H.; EDMONTON, B. S. Cyclosporine-induced gingival overgrowth: an ultrastructural stereologic study. Oral Surg Oral Med Oral Pathol, v. 65, p. 186-190, Apr. 1988.

15. MARSHALL, R. I.; BARTOLD, P. M. Medication-induced gingival overgrowth. Oral Dis, v. 4, p. 130-151, July 1998.

16. MERRITT, H.; PUTMAN, T. Sodium diphenyl-hydantoinate in the treatment of convulsive disorders. J Am Med Assoc, v. 111, p. 1068-1073, Oct. 1938.

17. MORISAKI, J.; KATO, K.; LOYOLA RODRIGUES, J. Nifedipine-induced gingival overgrowth in the presence or absence of gingival inflammation in the rats. $\mathbf{J}$ Periodontal Res, v. 28, p. 396-403, July 1993.

18. NASCIMENTO, A.; ALMEIDA, R. C. B.; BOZZO, L. et al. Interaction of phenytoin and inflammation induces gingival overgrowth in rats. J Periodontal Res, v. 20, p. 386-391, Sept. 1985.

19. RATEITSCHACK-PLÜS, E. M.; HEFTI, A.; LORTSCHER, R. et al. Initial observation that cyclosporin-A induces gingival enlargement in man. J Clin Periodontal, v. 10, p. 237-246, 1983.

20. ROITT, I.; BROSTOFF, J.; MALE, D. Imunologia. 5. ed. Manole, 1999, $423 \mathrm{p}$.

21. SCHINCAGLIA, G. P.; FORNITI, F.; CAVVALINI, R. Cyclosporin-A increases type I procollagen production in human gingival fibroblasts in vitro. $\mathbf{J}$ Oral Pathol Med, v. 21, p. 181-185, May 1992.

22. SEYMOUR, R.; SMITH, D. The effect of a plaque-control programme on the incidence and severity of cyclosporin-induced gingival changes. J Clin Periodontol, v. 18, p. 107-110, Nov. 1991.

23. SEYMOUR, R. Drug induced gingival overgrowth. Adverse Drug React Toxicol Rev, v. 12, p. 215-232, Aug. 1993.

24. SOMACARRERA, M.; HERNÁNDEZ, G.; ACERO, J. Localization of gingival overgrowth in heart transplant patients undergoing cyclosporin therapy. J Periodontol, v. 65, p. 666-667, Nov. 1994.

25. SUGANO, N.; ITO, K.; MURAI, S. Cyclosporin-A inhibits 
SPOLIDORIO, L. C.; GONZAGA, H. F. de S.; SPOLIDORIO, D. M. P. Análise quantitativa dos tecidos gengivais de ratos tratados com fenitoína e ciclosporina. Pesqui Odontol Bras, v. 14, n. 4, p. 327-333, out./dez. 2000.

collagenase gene expression via AP-1 and JNK suppression in human gingival fibroblasts. J Periodontal Res, v. 33, p. 448-452, Nov. 1998.

26. TIPTON, D. A.; STRICKLIN, G. P.; DABLOUS, M. K. Fibroblast hetereogenicity in collagenolytic response to cyclosporine. J Cell Biochem, v. 46, p. 152-165, Mar. 1991.

27. WASSEF, R.; COHEN, Z.; LANGE, B. Pharmacokinetic profiles of cyclosporine in rats. Influence of route adminis- tration and dosage. Transplantation, v. 40, p. 489-493, Feb. 1985.

28. WEIBEL, E. R. Stereological methods. New York : Academy Press, 1969.

29. WILLERHAUSEN-ZÖNNCHEN, B.; LEMMEN, C.; SCHUMACHER, U. Influence of cyclosporine-A on growth and extracelular matrix synthesis of human fibroblasts. J Cell Physiol, v. 152, p. 397-402, Oct. 1992.

Recebido para publicação em 03/05/00

Enviado para reformulação em 09/08/00

Aceito para publicação em 29/09/00 